\title{
Digital Volume Correlation: Progress and Challenges
}

\author{
Ante Buljac, Clément Jailin, Arturo Mendoza, Jan Neggers, Thibault Taillandier-Thomas, \\ Amine Bouterf, Benjamin Smaniotto, François Hild and Stéphane Roux \\ Laboratoire de Mécanique et Technologie (LMT) \\ ENS Paris-Saclay, CNRS, Université Paris-Saclay \\ Cachan, France
}

\begin{abstract}
Digital volume correlation consists in registering series of 3D images of experiments to yield 4D displacement fields. These 4D analyses have been conducted for the last two decades. Some achievements and current challenges are reviewed herein.
\end{abstract}

Keywords: DVC, ex situ tests, in situ tests, laminography, tomography

\section{INTRODUCTION}

Digital volume correlation (DVC) was introduced 20 years ago [1] and was first applied in biomechanics and then extended to the field of mechanics of materials [2]. Ten years ago, a first review was published by the pioneer of the technique [3]. At that time, results obtained with local registration algorithms were presented. Last year, a second review was published in which the global approaches were also presented [4]. The following discussions summarize some of the achievements over the last two decades and elaborate on some of nowadays challenges.

\section{BACKGROUND}

DVC is the 3D extension to 2D analyses carried out via digital image correlation (DIC) [5]. It consists in measuring 3D and 4D displacement fields (when image series are analyzed). DVC deals with series of 3D images that can be obtained with various imaging modalities. X-ray tomography is by far the most used modality in the field of biomechanics and mechanics of materials [4]. Stick-like samples are the favored geometry to be visualized. First performed on synchrotron beamlines, computed tomography is more often conducted on lab equipments. X-ray laminography was also used. It allows plate-like specimens to be imaged [6]. Other imaging modalities have also been used such as optical coherent tomography (OCT) or magnetic resonance imaging (MRI) [4].

Ex situ and in situ tests were then developed to image materials in various states of deformation. Specific testing machines had to be designed to be compatible with the imaging environment [7,4]. One critical aspect of in situ tests is that the applied loads and corresponding displacements have to be maintained constant during each scan. Furthermore, the environment of the sample can also be controlled in terms of humidity and temperature. These environmental conditions need to be made compatible with the fact that X-rays have to traverse the sample and all the equipment to be acquired by the detector.

\section{ACHIEVEMENTS}

For the first decade of DVC developments, only local approaches were implemented and utilized to measure 3D displacement fields [2]. Global approaches, which are mostly based on finite element discretizations of the displacement fields [8], were introduced at the end of the first decade. The second decade saw a significant increase in the number of results reported in the literature with both approaches [4].

In biomechanics, the failure of various bone structures were analyzed and compared with numerical predictions thanks to DVC analyses [4]. These studies were successful thanks to the multiscale nature of the microstructures that create very high contrast in biological materials imaged via X-ray tomography, MRI and OCT. 
Foams, be they ductile or brittle, are a first class of materials that are suited to DVC analyses. Various deformation and degradation mechanisms were revealed and quantified. This is particularly true for indentation tests for which most of the deformation process is hidden under the indentor (i.e., only 3D imaging can be used to analyze the in situ material behavior). The localization mechanisms in granular materials (e.g., sand) were also studied with DVC codes adapted to the grain shapes and their local kinematics.

Localized phenomena such as deformation bands and cracks have been studied on various engineering materials. Being a full-field measurement technique, DVC enables such phenomena to be quantified in a very extensive way. Various fields were used to detect and quantify cracks, namely, displacement, strain fields, and gray level residuals. This type of analyses required testing machines to be designed in order to apply, for instance, cyclic loading histories representative of low and high cycle fatigue regimes [7].

Validation and identification of constitutive models have started very recently [4], and they mostly dealt with nonlinear laws written at meso- or microscales. Such approaches are likely to develop more in the decade to come thanks to the achieved reliability and robustness of DVC analyses.

\section{CHALLENGES}

One of the first challenges is related to the suitability of various materials to DVC analyses. In DIC, the speckle patterns are very often created by spraying black and white paints onto sample surfaces. Particles have been added early on to enhance the volume contrast [2]. However, they may alter the behavior of the material of interest. Thanks to various improvements of DVC algorithms, the class of materials that could be analyzed has grown very substantially over the second decade.

Uncertainty quantifications have shown that the displacement uncertainties are generally higher with 3D imaging when compared with DIC procedures, namely, it is of the order of one tenth of a voxel (and one hundredth of a pixel) [4]. For many materials, this means that elastic strains cannot be measured, except when regularized or integrated approaches are implemented [9].

The fact that DVC deals with very large amounts of data becomes very demanding in terms of memory storage, computation time (especially for global analyses) and visualization. This observation calls for new numerical schemes to be implemented. When coupled with numerical simulations at the miscroscale for, say, validation purposes, the latter ones are also challenging. This trend becomes even more severe when the constitutive models are nonlinear with many parameters to calibrate.

The tomography and laminography processes involve acquisitions and 3D reconstructions that can be time consuming. In particular, in lab equipments, the acquisition of high quality images may last one hour or more depending on the selected resolution. Such scan durations do not allow materials with time-dependent behavior to be imaged. In synchrotron facilities, thanks to the brightness of the X-ray beams, these durations can be made significantly smaller but require faster rotation velocities [10]. An alternative route consists in combining DVC and reconstruction steps [11]. With such approaches, the in situ test in no longer interrupted and the radiographs are acquired on the fly [12], thereby allowing mechanical tests to be performed in a few minutes in lab-scale tomographic equipments.

\section{ACKNOWLEDGEMENTS}

Different parts of the above mentioned examples were funded by Agence Nationale de la Recherche under the grants ANR10-EQPX-37 (MATMECA), ANR-14-CE07-0034-02 (COMINSIDE), Saint Gobain, SAFRAN Aircraft Engines and SAFRAN Tech. It is a pleasure to acknowledge the support of BPI France within the DICCIT project, and ESRF for MA1006, MI1149, MA1631,MA1932, and ME1366 experiments. 


\section{REFERENCES}

[1] Bay B, Smith TS, Fyhrie DP, Saad M (1999) Digital volume correlation: three-dimensional strain mapping using Xray tomography. Exp Mech 39(3):217-226

[2] Bornert M, Chaix J-M, Doumalin P, Dupré J-C, Fournel T, Jeulin D, Maire E, Moreaud M, Moulinec H (2004) Mesure tridimensionnelle de champs cinématiques par imagerie volumique pour l'analyse des matériaux et des matériaux et des structures. Instrumentation, Mesure, Métrologie 4:43-88

[3] Bay B (2008) Methods and applications of digital volume correlation. J Strain Anal Eng Des 43(8):745-760

[4] Buljac, A., Jailin C., Mendoza A., Neggers J., Taillandier-Thomas T., Bouterf A., Smaniotto B., Hild F., Roux S. (2018) Digital Volume Correlation: Review of Progress and Challenges, Exp Mech 58:661-708

[5] Sutton MA, Orteu JJ, Schreier H (2009) Image correlation for shape, motion and deformation measurements: basic concepts, theory and applications. Springer, New York

[6] Morgeneyer TF, Helfen L, Mubarak H, Hild F (2013) 3D Digital Volume Correlation of synchrotron radiation laminography images of ductile crack initiation an initial feasibility study. Exp Mech 53(4):543-556

[7] Buffière J-Y, Maire E, Adrien J, Masse J-P, Boller E (2010) In situ experiments with X-ray tomography: an attractive tool for experimental mechanics. Exp Mech 50(3):289-305

[8] Roux S, Hild F, Viot P, Bernard D (2008) Three-dimensional image correlation from x-ray computed tomography of solid foam. Compos Part A Appl Sci Manuf 39(8):1253-1265

[9] Bouterf A, Roux S, Hild F, Adrien J, Maire E, Meille S (2014) Digital volume correlation applied to X-ray tomography images from spherical indentation tests on lightweight gypsum. Strain 50(5):444-453

[10] Maire E, Le Bourlot C, Adrien J, Mortensen A, Mokso R (2016) 20-Hz x-ray tomography during an in situ tensile test. Int J Fract 200(1):3-12

[11] Leclerc H, Roux S, Hild F (2015) Projection savings in CT-based digital volume correlation. Exp Mech 55(1):275287

[12] Jailin C, Bouterf A, Poncelet M, Roux S (2017) In situ $\mu C T$ mechanical tests: fast 4D mechanical identification. Exp Mech 57(8):1327-1340 